\title{
A OPÇÃO PELA LITERATURA NA TELEVISÃO BRASILEIRA: O EXEMPLO DAS MINISSÉRIES DA REDE GLOBO
}

\author{
MARIA TEREZA AMODEO \\ PONTIFÍCIA UNIVERSIDADE CATÓLICA DO RIO GRANDE DO SUL \\ PORTO ALEGRE, RIO GRANDE DO SUL, BRASIL \\ MTAMODEO@PUCRS.BR
}

HTTP://DX.DOI.ORG/10.5902/2316882X29275 


\section{A OPÇÃO PELA LITERATURA NA TELEVISÃO BRASILEIRA: O EXEM- PLO DAS MINISSÉRIES DA REDE GLOBO}

Resumo: Este artigo analisa o contexto em que surgiram as minisséries da Rede Globo de Televisão que utilizam obras da literatura brasileira como fonte como possibilidades pós-modernas de identidade cultural no âmbito da globalização, deixando marcas importantes que contribuem para definir o gênero e expandir o Brasil além de suas fronteiras. As minisséries O Tempo e o vento, grande sertão: veredas e Memorial de Maria Moura em foco apresentam formas diferentes de aproveitamento dos textos literários.

Palavras-chave: televisão; minisséries; literatura; arte; gênero.

\section{LA OPCIÓN POR LA LITERATURA EN LA TELEVISIÓN BRASILEÑA: EL EJEMPLO DE LAS MINISTERIAS DE LA RED GLOBO}

Resumen: Este artículo analiza el contexto en que surgieron las miniseries de la Red Globo de Televisión que utilizan obras de la literatura brasileña como fuente de posibilidades post-modernas de identidad cultural en el marco de la globalización, dejando marcas importantes que contribuyen a definir el género y expandir Brasil más allá de sus fronteras. Las miniseries O Tempo e o vento, grande sertão: veredas e Memorial de Maria Moura en foco presentan formas diferentes de aprovechamiento de los textos literarios.

Palabras clave: televisión; miniseries; literatura; arte; de género.

THE OPTION FOR LITERATURE IN BRAZILIAN TELEVISION: THE EXAMPLE OF MINISERIES OF THE GLOBO NETWORK

Abstract: This article analyzes the context in which the miniseries of the Globo Television Network that use works of the Brazilian literature as source as postmodern possibilities of cultural identity in the ambit of globalization appeared, leaving important marks that contribute to define the genre and to expand Brazil beyond its borders. The miniseries $O$ Tempo e 0 vento, grande sertão: veredas e Memorial de Maria Moura in focus present different forms of exploitation of literary texts.

Keywords: TV; miniseries; literature; art; genre.

Rev.Cad.Comun. Santa Maria, v.22, n.1, art 6, p.123 de 141, jan/abr.2018 


\section{CENAS DOS PRÓXIMOS CAPÍTULOS}

Em tempos de seriados televisivos importados, oferecidos tanto por canais abertos como fechados de televisão, ou disponibilizados via internet por empresas de entretenimento estrangeiras, mediante tarifas mensais, propõe-se uma reflexão sobre as minisséries televisivas brasileiras da Rede Globo de Televisão que se valem de obras literárias como textos-fonte.

Não se trata de uma postura sectária, purista, que pretende valorizar produções localistas em detrimento das estrangeiras, que fazem tanto sucesso de audiência, mas de avaliar um tipo de modalidade cultural com características muito específicas, que, ao mesmo tempo em que fala do Brasil para os telespectadores locais, também o faz para o exterior, sem incidir em estereótipos comumente associado ao país.

A partir de um percurso que se inicia com a instauração da televisão no Brasil, a Rede Globo passa a produzir, desde a década de 70 do século XX, narrativas seriadas que se apoiam, de formas muito variadas, em grandes obras da literatura nacional. É com o avanço das inovações tecnológicas que as minisséries se impõem como uma modalidade muito peculiar. Sem se configurar como um gênero fechado, definido por características específicas, mas, sim, de uma modalidade aberta às emergências da contemporaneidade, que se apoia na força da literatura, por essa oferecer universos ficcionais autônomos, de forte sentido imaginativo e apelo estético, através de elementos articulados de forma coerente e altamente organizada, em que a representação/expressão de questões atinentes ao homem já está trabalhada.

Assim, com o objetivo de focalizar as minisséries da Rede Globo que utilizam obras da literatura brasileira como fonte, o presente artigo analisa o contexto em que surgiram e o período em que efetivamente se impõem - a partir do final da década de 80 do século XX -, como possibilidades de veiculação de identidades culturais associadas ao país no âmbito da globalização, deixando marcas importantes que contribuem para definir o gênero e expandir o Brasil além de suas fronteiras.

Para tanto, propõe-se um breve histórico sobre a televisão no país, que visa contextualizar a produção das minisséries, em especial as que têm obras literárias como textos-fonte, no âmbito da globalização cultural; discutindo-se algumas particularidades da sintaxe visual da televisão,

Rev.Cad.Comun. Santa Maria, v.22, n.1, art 6, p.124 de 141, jan/abr.2018 
processo que dessacraliza a literatura neste contexto em que conceitos relacionados a território, fronteira e identidade se reconfiguram. Nessa medida, as minisséries, $O$ tempo e o vento, Grande sertão: veredas e Memorial de Maria Moura, produzidas nas décadas de 80 e 90, constituem fonte para esta reflexão, pois apresentam formas diferentes de aproveitamento dos textos literários, pontuando-se elementos que podem contribuir para caracterizar o gênero em questão.

\section{A TELEVISÃO NO BRASIL}

Do momento de seu surgimento, na década de 50, até os anos 70, a televisão brasileira transmite o universo de ideias da modernidade. É nesse período que o veículo se instala no país, ensaia procedimentos e estabelece-se de forma definitiva na cultura para, então, incorporar as conquistas tecnológicas que os anos oitenta e noventa ofereceram - período que constitui a segunda fase do desenvolvimento da televisão no Brasil.

Assim, da ousada aventura empreendida por Assis Chateaubriand nesse universo até então totalmente desconhecido dos povos latino-americanos, às múltiplas possibilidades contemporâneas, a história da televisão brasileira expressa os moldes como o País se inseriu no contexto econômico-político-social-cultural mundial.

Ainda na década de 50, segundo Marcondes Filho, a televisão brasileira viveu o período de instalação dos sistemas de transmissão, de exploração e de descobertas das possibilidades do recurso (1994, p.27). Embora o veículo se constituísse na grande inovação em termos de comunicação, não ousava no que se refere à programação: mantinha a veiculação de formas tradicionais de narração, seguindo um padrão convencional, assim como faziam o rádio e o cinema - com o diferencial de que o tratamento da imagem mais lembrava o do teatro. A programação baseava-se em telenovelas, programas humorísticos e telejornalismo. Os profissionais, egressos do rádio, do cinema, do teatro e do jornalismo, experimentavam o novo veículo, realizando uma simples transposição das realizações anteriores.

Na década de sessenta, o veículo é explorado de forma mais criativa, já que o capital necessário à produção televisiva circula com maior naturalidade pela crescente participação dos anunciantes, havendo, também, um maior número de emissoras concorrentes. É quando a televisão se torna meio de atingir as grandes massas. Conforme Marcondes Filho, 
Essa fase vai prolongar-se até os anos 70 em que, no Brasil, especialmente, a TV Globo assume a liderança absoluta da audiência. Através da introdução de um sofisticado sistema de produção e distribuição da ampliação dos meios de reprodução de seus sinais pelo país inteiro e de uma filosofia nitidamente empresarial, caracterizada pela introdução de princípios de rentabilidade e eficiência até então desconhecidos, pode-se dizer que, agora sim, a televisão amadurece. Deixa de ser um meio de comunicação que apenas dá uma nova roupagem às peças teatrais, ao humor radiofônico, ao jornal, para ser um sistema que cria a sua própria forma de dizer as coisas. A linguagem da televisão nasce aqui. (1994, p. 29)

O processo brasileiro de implantação da televisão ocorreu de forma inversa ao que se sucedeu nos Estados Unidos - o que foi determinante para o tipo de programação que se instituiu no país. Lá, quando se iniciou a indústria da televisão, a do cinema já era uma realidade; estabeleceu-se um acordo no sentido de que esta exploraria a ficção, o humor, a dramaturgia, enquanto as emissoras televisivas fariam jornalismo e esporte. Com o advento do videoteipe e as possibilidades de transmissão ao vivo, a modalidade que explorava o esporte cresceu, bem como a produção da dramaturgia associada a Hollywood. Sem possuir uma indústria de cinema já estabilizada que pudesse oferecer bases para o novo empreendimento, e também sem a intervenção estatal que ocorreu na Europa, a televisão brasileira (assim como a mexicana e a venezuelana) passou a "criar uma estrutura de megaprodução" (GLEISER, 1995, p.22) - o que favoreceu significativamente as narrativas ficcionais.

Ao final da década de oitenta, a televisão passa a dominar de forma plena o mercado de informações. A incorporação de novos sistemas eletrônicos de transmissão permite a expansão dos emissores de comunicação, bem como das mensagens. É dessa maneira que "o monopólio em torno de um único transmissor" - razão de crítica na fase anterior - se rompe (MARCONDES FILHO, 1994, p. 32).

Nos últimos anos da década de 90, o Brasil assistiu à introdução da televisão por assinatura, através dos inúmeros satélites de comunicação em órbita mundial que disponibilizam um número cada vez maior de canais, viabilizando-se a internacionalização da televisão. Acresce-se a essa possibilidade, a comunicação interpessoal através da Internet, otimizando o processo de comunicação a distância, sem o envolvimento corpóreo, que se iniciou com o telégrafo e chegou à televisão, a qual hoje incorpora

Rev.Cad.Comun. Santa Maria, v.22, n.1, art 6, p.126 de 141, jan/abr.2018 
todos esses avanços. A esse respeito, Luiz Gleiser anunciava, em 1993, o que hoje é uma realidade:

Está havendo uma globalização muito rápida e violenta da distribuição de programação de televisão, cuja consequência será o que se poderia chamar de fim dos guetos nacionais. Assim, como já ocorreu com o cinema nacional e a música brasileira, vamos sair do gueto em que vivemos em termo de televisão. $\mathrm{E}$ explosão é inevitável. [...] A indústria da televisão de massa será grandemente reduzida. (GLEISER, 1995, p.11)

Os altos índices de audiência da Rede Globo pareciam indicar que a emissora não assumiria essa nova aventura. No entanto, a demanda tecnológica e a necessidade de ampliar os mercados impuseram a instalação da Globosat. Os canais por assinatura nacionais passaram a conviver com os estrangeiros que chegavam ao país.

Nesse sentido, o quadro de possibilidades oferecidas ao telespectador se ampliou significativamente: o número de canais de televisão segmentada é muito grande, convivendo com os canais de circuito aberto, que buscam desesperadamente ganhar a audiência, cada vez mais disputada diante de tantas opções. É fato que a fusão das três grandes indústrias - a da informática, a da televisão e a da comunicação - promove uma enorme oferta de programas: o telespectador tem a sua disposição bons produtos culturais, que convivem com os de qualidade duvidosa.

A televisão brasileira produz basicamente três tipos de programas: os de telejornalismo - que devem focalizar a informação —, os "programas de auditório" - dirigidos principalmente para o entretenimento - e as narrativas ficcionais - que transitam nas áreas das outras duas modalidades, alcançando, por vezes, resultados artísticos que merecem ser avaliados com critérios específicos.

\section{AS NARRATIVAS FICCIONAIS DA TELEVISÃO}

As narrativas ficcionais - especialmente as telenovelas - acompanharam o surgimento da televisão no país, tendo sido determinantes para o assentamento do veículo. Elas se constituíram de forma a priorizar o esquema comercial assumido - o que comprometeu, na maioria das vezes, a sua qualidade artística. Já no ano seguinte à instalação do veículo, Sua vida me pertence, de Walter Foster, funda, na TV Tupi de São Paulo, a his-

Rev.Cad.Comun. Santa Maria, v.22, n.1, art 6, p.127 de 141, jan/abr.2018 
tória do gênero, embora ainda sem se constituir como emissão diária - o que só ocorre a partir de 1963 (ORTIZ, 1991).

Apesar da ancestralidade ligada ao folhetim francês do século XIX, às radionovelas e mesmo às soap operas norte-americanas e às mexicanas, a telenovela brasileira tem uma expressão muito peculiar, que alia anos de experiências, qualidade técnica e tramas que, de alguma forma, interessam ao público brasileiro e estrangeiro.

As produções da Rede Globo, tanto as telenovelas como as minisséries, exigem grandes investimentos no que se refere a recursos de imagens utilizados, atores, diretores, adaptadores e textos escolhidos, mas têm, em geral, a seu tempo, retorno financeiro, uma vez que são exportadas para todo o mundo e, em especial as minisséries, mais recentemente, também comercializadas em formato de DVD, direto ao consumidor.

Sobre o caminho percorrido pelas narrativas televisivas cabe a referência de Dias Gomes, apontada por Ismael Fernandes, no que se refere à possibilidade de certas séries ficcionais brasileiras de subverterem o discurso maniqueísta, cheio de chavões tradicionais, promovendo inovações no que se refere a temas e linguagem. (FERNANDES, 1994, p. 24)

\section{A BUSCA PELA LITERATURA}

O aproveitamento de obras literárias efetivamente contribuiu para a qualidade dos textos televisivos, pois, apesar de toda a avalanche de possibilidades culturais transmitidas pela televisão, as adaptações de textos literários para a televisão acompanharam a evolução do veículo no país inaugurando formas, repetindo e/ou rejeitando procedimentos, inovando e incorporando as facilidades tecnológicas.

Embora várias emissoras tenham optado pela adaptação de textos literários como base para as narrativas ficcionais - especialmente telenovelas - , foi a Rede Globo a que mais se destacou nesse sentido, uma vez que iniciou a prática ainda na década de 60 , renovando-se ao longo de várias décadas.

Muitas obras literárias foram adaptadas pela Rede Globo em diferentes formatos, tais como telenovelas, minisséries ou microsséries. Trata-se de um procedimento bastante frequente, que vem se realizando pelo menos há seis décadas. O procedimento se justifica como uma tendência típica da globalização cultural que, através das grandes mídias eletrôni-

Rev.Cad.Comun. Santa Maria, v.22, n.1, art 6, p.128 de 141, jan/abr.2018 
cas, apela para o diferente com o fim de capitalizar audiências, criando o interesse pelo particular, pelo local, aproximando realidades distantes geográfica e historicamente. Ao longo desse período, a emissora reforçou o espaço da literatura no contexto televisivo, na medida em que as histórias se constituem em quadros coerentemente articulados de retalhos do Brasil.

Essa opção sugere que pôr em evidência representações da identidade plurifacetada do País não só conquista plateias nacionais, mas constitui-se como um forte argumento comercial na rede internacional de negócios televisivos, especialmente as que se moldaram no formato de minisséries.

\section{A LITERATURA NAS MINISSÉRIES}

Produzidas a partir de 1982, as minisséries acompanharam a segunda fase da televisão brasileira, marcada pelas novas possibilidades oferecidas pela tecnologia, através dos incontáveis recursos da computação eletrônica. Seguiram, portanto, a tendência da época ao conjugarem linguagens e gêneros diferentes.

Embora como sempre conformadas às exigências do veículo, no que se refere a custos, patrocínio, níveis de audiência e retorno de capital, bem como à exposição diária, na forma seriada, as minisséries dos primeiros tempos eram produzidas com maior autonomia e coerência interna em relação às telenovelas. Elas só eram transmitidas após terem sido completamente produzidas. Diferentemente das telenovelas, a recepção do público telespectador não costumava alterar a concepção original do programa (o que hoje seguramente já se modificou). O gosto do público, portanto, era considerado apenas a partir das experiências anteriores, isto é, os realizadores deveriam avaliar os fracassos e sucessos passados para verificar a possível recepção da produção pelo público - elemento imprescindível, pois justificava o investimento dos patrocinadores.

Assim, sem o controle rígido de audiência que, hoje, determina a continuidade de qualquer produção televisiva, os realizadores das minisséries podiam produzir trabalhos mais criativos, mais artísticos, (o que, definitivamente, costumava captar um público mais exigente); por outro lado, corriam risco de um fracasso em termos de audiência. Dessa forma, o espaço de criação era muito mais amplo do que nas outras modalidades narrativas televisivas. E, seguramente, a possibilidade de se valerem de obras

Rev.Cad.Comun. Santa Maria, v.22, n.1, art 6, p.129 de 141, jan/abr.2018 
literárias como textos de base contribui significativamente para garantir o caráter artístico das minisséries.

\section{A SINTAXE VISUAL E A LITERATURA}

Diferentemente da literatura (que pode ser lida, relida, interpretada e reinterpretada) e do cinema - por se tratar de uma emissão de aproximadamente duas horas, que pode facilmente ser apreciada mais de uma vez -, as narrativas televisivas não contam com a possibilidade de releitura, embora o telespectador possa gravar os capítulos, mas o procedimento não visa a releituras posteriores, dada a extensão dos programas. Sobre mensagem televisiva que se dirige a uma só emissão, Artur da Távola (1984) salienta que ela se define pela "estética da superficialidade".

Pressionado pela falta de tempo para ensaios, o ator desenvolve, segundo o crítico, "mecanismos criativos paralelos" (p.19), ou seja, seu potencial criativo lhe dá a medida para construir a personagem. Diferentemente do teatro, em que o profissional tem condições de aprofundar a sua personagem ao longo de vários meses de ensaio, na televisão o processo se realiza durante a própria representação. Embora a relação entre a personalidade do ator e a personagem seja tensa em qualquer tipo de dramaturgia, na televisão se torna diversa e mais complexa. O tipo de exposição do ator se dá, portanto, muito mais através dos "mecanismos empáticos diversos", considerando-se que a "sintaxe visual" da televisão "usa muito mais o rosto que o corpo do ator, sem poder prescindir deste" (TÁVOLA, 1984, p.71).

A fim de favorecer a comunicação mais imediata, os atores são escolhidos para determinados papéis de acordo com o "ponto e o pacto empáticos" já estabelecidos - o que define uma comunicação extrapersonagem. Nas minisséries, ocorre uma composição de personagem que conta com uma dupla disposição: ao mesmo tempo em que os atores já conhecidos do público de televisão - evidenciam aqueles elementos que constituem as suas marcas, existe a possibilidade de uma construção mais cuidada das personagens, permitindo a "revelação de uma individualidade, enquanto 'personificação' de uma 'verdade' socioeconômica, que representa uma determinada visão política, uma antropologia étnico-caracterológica" - conforme registra Távola (1984, p 79) ao se referir aos elementos que devem constituir a construção da personagem de televisão.

Rev.Cad.Comun. Santa Maria, v.22, n.1, art 6, p.130 de 141, jan/abr.2018 
"O ator é um médium", segundo o crítico, pois, ao mesmo tempo em que deve representar os anseios do espectador - o que resulta em audiência e justifica o investimento dos patrocinadores - , deve expressar a particularidade da personagem enquanto representação simbólica do real, explorar suas próprias características empáticas, bem como atender às especificações do autor (Ibidem, p.84). Esse aspecto, em se tratando de obras literárias adaptadas para a televisão, torna-se ainda mais complexo, considerando-se que o conceito de autoria se redimensiona e deixa evidente a convivência entre campos antes impossíveis de se avizinharem.

\section{A DESSACRALIZAÇÃO DA LITERATURA}

O procedimento deve ser entendido no contexto de final do século $\mathrm{XX}$, em que se começam a neutralizar os limites estabelecidos entre as artes, bem como entre as diferentes áreas do conhecimento humano. Desautoriza-se o conceito de obra de arte como algo sagrado, que permite uma vivência única, reatualizada a cada apreciação - como uma experiência mítica.

Ao ser transposta para a televisão, a obra é submetida a processos que rompem com a concepção estética clássica, que tem seu fundamento na aura, no valor cultual e a na autenticidade. Walter Benjamin (1990) aponta para essa renovação do estatuto artístico quando trata da arte em tempos de reprodutibilidade técnica.:

Os produtos culturais contemporâneos devem ser considerados a partir de parâmetros vinculados aos avanços tecnológicos. A modalidade em questão, ao mesmo tempo em que guarda traços de contiguidade em relação à que lhe deu origem, é marcada de forma significativa por novos elementos.

Os meios de comunicação de massa, nessa medida, permitem a democratização da cultura dita superior, antes disponível apenas a uma camada elitizada da sociedade: o público da obra literária adaptada para a televisão amplia-se numa dimensão incomparável àquela que, no melhor dos prognósticos, previu o autor. É verdade que ela é modificada, contudo a grande massa tem a oportunidade de conhecer o que antes lhe era absolutamente inatingível.

Submetidas ao poderoso meio de comunicação de massas, que é a televisão, as obras literárias provocam uma série de reações que envol-

Rev.Cad.Comun. Santa Maria, v.22, n.1, art 6, p.131 de 141, jan/abr.2018 
vem os seus receptores, cujo perfil é pouco definido. Essas plateias tanto podem ser compostas por intelectuais, como por críticos literários, por leitores comuns das obras, ou mesmo por telespectadores sem qualquer informação acerca dos originais - para quem o universo literário passa a ser aquele veiculado pela televisão, o que pode, eventualmente, remeter à leitura da obra. De qualquer forma, apesar da indefinição relativa à categorização do público telespectador, os significativos índices de audiência alcançados por esse tipo de programação levam a crer na abrangência dessas plateias, que constituem uma grande massa - as maiorias silenciosas, na expressão talvez um pouco catastrófica de Jean Baudrillard (1993), que, no entanto, expressa a dificuldade de identificação desses interlocutores contemporâneos, a quem são dirigidas tais modalidades culturais criadas no interior da sociedade de consumo.

As críticas, mais ou menos especializadas, em geral ressaltam as diferenças entre a obra literária e a forma televisiva. Avaliações que apontam para aspectos relacionados às dicotomias ortodoxas entre literário $X$ não literário, arte $\mathrm{X}$ não arte, ou, ainda, arte erudita $\mathrm{X}$ arte popular revelam a necessidade de redimensionar a questão por meio de uma abordagem menos simplista, que considere a infinidade de realidades artificiais produzidas industrialmente, definidoras da concepção de mundo do sujeito contemporâneo.

\section{O MUNDO GLOBALIZADO - TERRITÓRIOS, FRONTEIRAS E IDEN- TIDADES}

A partir da segunda metade do século XX, a reprodução em escala global do capital passa a determinar a forma como se organiza a produção, a distribuição, a troca e o consumo. Há uma mudança nos significados tradicionalmente atribuídos aos conceitos de países, uma vez que as realidades interpenetram-se: "desterritorializam-se coisas, gentes e idéias" (DUARTE, 1998, p.74).

Ocorre uma neutralização de lugar e distância, que determina um novo e complexo quadro social: da convivência entre culturas, religiões, línguas e raças diferentes surgem problemas de ordem social, econômica e política - multiplicam-se seitas, grupos, atitudes radicais ou violentas. Criam-se, portanto, situações que, se por um lado desafiam a consciência dos intelectuais e das pessoas em geral, produzem um grande contingen-

Rev.Cad.Comun. Santa Maria, v.22, n.1, art 6, p.132 de 141, jan/abr.2018 
te que vive perdido em meio às idiossincrasias dessa realidade globalizante. É, portanto, fato que a "Terra torna-se o território da humanidade": “O planeta Terra está tecido por muitas malhas, visíveis e invisíveis, consistentes e esgarçadas, regionais e universais. (IANNI, 1996, p.29)

O homem contemporâneo, portanto, transita em diferentes culturas, mas também transportando marcas adquiridas no seu local de origem. Ao mesmo tempo em que os meios de comunicação veiculam a ideia de mundo globalizado, como uma civilização planetária unificada, multiplicam-se os conflitos regionais.

Num universo tão complexo, em que se multiplicam e se transmitem signos mutáveis, quaisquer divisões dicotômicas - como Ocidente e Oriente, por exemplo - revelam-se simplistas. Portanto, à ideia de globalização integram-se as diferenças locais, num processo de influências recíprocas.

Trata-se de um tempo de "abolição da fronteira entre arte e vida cotidiana: a derrocada da distinção hierárquica entre alta-cultura e cultura de massa/popular; uma promiscuidade estilística, favorecendo o ecletismo e a mistura de códigos; paródia, pastiche, ironia, diversão e a celebração da 'ausência de profundidade' da cultura; o declínio da originalidade/genialidade do produtor artístico e a suposição de que a arte pode ser somente repetição. (FEATHERSTONE, 1995, p.25)

Jameson (1993, p. 26) afirma que, do ponto de vista acadêmico, sempre houve uma intenção evidente na preservação do que se convencionou pertencer ao campo culto, à cultura elitista, "em oposição ao meio circundante de prosaísmo, breguice e kitsch, dos seriados de TV e da cultura Reader's Digest". Há, contudo, nos procedimentos contemporâneos, um envolvimento, uma empatia em relação a essas formas, antes marginalizadas do contexto intelectualizado.

Ao mesmo tempo, a simplicidade da natureza humana parece estar distante das formas culturais elaboradas, complexas e sofisticadas da contemporaneidade, o que se explica pela interferência direta das máquinas na circulação de conhecimentos, dos próprios homens e das imagens, conforme salienta Jean Lyotard (1993, p. 4): "a natureza do saber é significativamente alterada, uma vez que este só poderá ser veiculado e, consequentemente, legitimado o que for transformado pelos meios eletrônicos".

Qualquer análise da experiência contemporânea, portanto, deve 
contemplar, além dos referenciais, "as práticas culturais concretas e as balanças de poder em mutação desses grupos envolvidos na produção, classificação, circulação e consumo de bens culturais pós-modernos" (FEATHERSTONE, 1995, p. 23).

Stuart Hall (1998) aponta para os aspectos contraditórios inerentes à questão, que levam a definições de caráter provisório pois o conceito de "identidade" é demasiadamente complexo, muito pouco desenvolvido e muito pouco compreendido na ciência social contemporânea para ser definitivamente posto à prova.

Evidencia-se o caráter transitório dos conceitos formulados num contexto permeável a tantas modificações como o contemporâneo, em que "o espaço e o tempo se cruzam para produzir figuras complexas de diferença e identidade, passado e presente, interior e exterior, inclusão e exclusão", conforme salienta Homi K. Bhabha (1998, p. 19).

O sujeito pós-moderno convive com um número tão grande de sistemas de significação e de representação cultural — transmissores de tantas identidades - que a sua fragmenta-se, desloca-se, descentra-se, levando- o a questionar-se acerca da sua verdadeira identidade cultural, oscilando entre a opção de valorização do local — o nacional — ou do global.

Embora o discurso sobre a cultura nacional não seja assim tão moderno, a contemporaneidade, ao mesmo tempo em que transita entre o passado e o futuro, expressa o desejo de incorporar o universal concomitantemente à adesão ao particular. Sobre a questão, Homi Bhabha lembra que o conceito de cultura passa a abranger não só as formas canônicas de arte, mas toda a espécie de textualidade simbólica que envolve o dado cotidiano numa "aura de individualidade", numa "promessa de prazer" (BHABHA, 1998, p. 240).

A articulação social da diferença, da perspectiva da minoria, é uma negociação complexa, em andamento, que procura conferir autoridade aos hibridismos culturais que emergem em momentos de transformação histórica. O "direito" de se expressar a partir da periferia do poder e do privilégio autorizados não depende da persistência da tradição; ele é alimentado pelo poder da tradição de se reinscrever através das condições de contingência e contraditoriedade que presidem sobre as vidas do que estão "na minoria". O reconhecimento que a tradição outorga é uma forma parcial de identificação. Ao reencenar o passado, este introduz outras temporalidades culturais incomensuráveis na invenção da tradição. Esse

Rev.Cad.Comun. Santa Maria, v.22, n.1, art 6, p.134 de 141, jan/abr.2018 
processo afasta qualquer acesso imediato a uma identidade original ou a uma tradição "recebida". Os embates de fronteira acerca da diferença cultural têm tanta possibilidade de serem consensuais quanto conflituosos; podem confundir nossas definições de tradição e modernidade, realinhar as fronteiras habituais entre o público e o privado, o alto e o baixo, assim como desafiar as expectativas normativas de desenvolvimento e progresso. (BHABHA, 1998, p. 21)

Portanto, considerar a cultura nacional como fonte de significados culturais, foco de identificação e sistema de representação, conforme aponta Hall, não significa prescindir da ideia da diferença.

Nessa perspectiva, a questão da autenticidade relativiza-se na medida em que reinterpretar a realidade diz respeito a uma construção simbólica que elimina dúvidas acerca da veracidade ou da falsidade do que é produzido. Portanto, não existe uma única identidade, mas uma pluralidade de identidades construídas em diferentes momentos da história, por diferentes grupos sociais, condicionadas por interesses ideológicos.

Nesse sentido, ao se apropriar de textos que possuem o aval do cânone literário, a televisão brasileira, como meio da cultura de massa incorporado aos avanços tecnológicos que permitem a circulação internacional de seus produtos, imprimiu suas marcas na adaptação de linguagens. Dessa forma, atua sobre os significados das obras, reiterando ou modificando sentidos que interferem nas formas de representação simbólica do elemento nacional veiculadas pelos originais.

Não se trata de questionar a veracidade da formação do povo gaúcho, assim como é apresentada por Erico Verissimo em O Tempo e o Vento; ou a fidelidade do retrato do jagunço por Guimarães Rosa, em Grande Sertão: Veredas; ou, ainda, a mitificação da lendária Maria Moura em Memorial de Maria Moura de Rachel de Queiroz.

Assim, avaliando-se como as representações simbólicas da identidade nacional concebidas nos romances brasileiros são transpostas par a televisão relaciona-se a "capacidade de mobilização" dos originais, aquilo que os torna verossímeis e os impõe enquanto representação simbólica. Porque concebidas com vistas não apenas ao mercado interno, mas também ao externo, tais produções devem incorporar elementos que garantam a sua circulação internacional, os quais podem transformar as representações simbólicas dos originais literários.

Rev.Cad.Comun. Santa Maria, v.22, n.1, art 6, p.135 de 141, jan/abr.2018 
Os processos de caráter globalizante - especialmente reconhecidos pelas mudanças das categorias de tempo e espaço - que atingem as comunidades e as organizações, além dos limites das nações, promovem uma revisão no conceito de identidades culturais, afetando o papel identitário atribuído à literatura desde o Romantismo e redefinindo a relação entre universo imaginário e linguagens. Estas podem fundir-se, acrescentando e/ou substituindo signos umas às outras, num processo reinterpretativo do que uma ou outra institui como matéria imaginativa, gerando visões instáveis, provisórias daquilo que caracteriza a cultura de indivíduos, grupos ou países.

São essas metamorfoses entre sistemas culturais que possibilitam pensar o literário não contra o pano de fundo dos recursos tecnológicos de difusão em massa, mas dentro deles, e que legitimam a consideração das adaptações televisivas dos textos literários como objeto não de um mero comparativismo, mas de uma tensão entre local/global que se instila no consumo de produtos culturais de todas as áreas.

Assim, as considerações aqui apresentadas se referem principalmente ao período de instauração do gênero "minisséries televisivas baseadas em obras literárias no Brasil”, o que corresponde às décadas de 80 e 90. De forma ousada, os realizadores de O Tempo e o Vento (1985), Grande Sertão: Veredas (1985) e Memorial de Maria Moura (1994) valeram-se das possibilidades disponíveis pela tecnologia da televisão à época, das experiências adquiridas especialmente com as telenovelas e do material literário - concebido fora desse circuito -, deixando um legado que merece ser examinado, porque original, inovador e determinante para definir o gênero em questão.

\section{FOCO NAS MINISSÉRIES}

\section{Primeira Parte - Reinterpretando a Saga Rio-Grandense}

No caso de O Tempo e o Vento, ocorrem modificações, contudo não há uma submissão do universo engendrado por Erico Verissimo ao domínio de uma linguagem visual, que priorize a comunicação imediata e efêmera. Nesse caso, ao ser adaptada para o veículo, a obra literária sofre modificações significativas, contudo, a série televisiva mantém, conforme aponta Sérgio Caparelli (1986, p. 132), "laços de origem e contiguidade" em relação ao texto de Erico Verissimo.

Rev.Cad.Comun. Santa Maria, v.22, n.1, art 6, p.136 de 141, jan/abr.2018 
A história do romancista, que oferece um universo ficcional representativo da gesta sul-rio-grandense, permanece na narrativa televisiva enquanto expressão de valores geralmente associados a essa identidade cultural e evidenciados pelas personagens. A par das diferenças de percursos, dos novos elementos e contextos que seguramente modificam a carga semântica original da obra de Erico Verissimo, o universo narrado na televisão deixa entrever uma concepção identitária do povo do sul que se caracteriza por sua capacidade de luta, força, determinação, coragem e perseverança, que se alterna em períodos de paz e de guerra, de harmonia e de violência. Tais elementos, que compõem o universo ficcional da obra literária - relacionados a buscas e a conquistas características do sul do País -, são capazes de mobilizar os destinatários do texto enquanto leitores e como telespectadores.

\section{Segunda Parte - A Redesconstrução do Jagunço}

A conjunção entre obra literária e meios tecnológicos permitiu a difusão em massa de um novo produto cultural que possibilita a plateias nacionais e estrangeiras uma representação simbólica ainda complexa da identidade do jagunço da região de Minas, oferecendo uma reinterpretação do universo ficcional tão habilmente engendrado por Guimarães Rosa.

Embora o processo de construção da narrativa tenha sido modificado, privilegiando a linearidade, com o fim de se moldar à tipologia estrutural da narrativa televisiva - e resultando numa simplificação do percurso de Riobaldo na busca de si mesmo — os paradoxos de sua vida traduzem-se pela forma como são apresentados visualmente os episódios vividos.

Os grandes temas da obra de Guimarães Rosa — tais como a busca do autoconhecimento, o livre arbítrio, a atração do mal, o impulso vertente da natureza virgem, personificados pelas personagens, embora veiculados através dos processos típicos das narrativas de televisão, não incidem nos estereótipos generalizantes convencionais.

O trabalho de adaptação realizado reconfigura a obra, redimensionando o sertão de Guimarães Rosa e permitindo que ele se revele através de um diálogo entre texto, inovações tecnológicas e capacidade artística dos atores.

\section{Terceira Parte - A Transfiguração dos Excluídos}

Os dramas vividos pelos excluídos do Nordeste - representados por Maria Moura, padre José Maria e Marialva —, na minissérie, assumem significados muito diferentes dos originalmente configurados na obra, jus-

Rev.Cad.Comun. Santa Maria, v.22, n.1, art 6, p.137 de 141, jan/abr.2018 
tificada apenas pela composição de uma minissérie plasticamente muito bem construída.

Mesmo que se entenda a circulação internacional da obra como um êxito da adaptação, o processo de ajuste ao formato televisivo por que passa a obra de Rachel de Queiroz desfigura o caráter identitário do romance, por impor à narrativa estratégias tradicionalmente utilizadas na produção das telenovelas e telesséries: os conflitos de personalidade, as lutas e correrias, a vingança, os amores contrariados. A par dos episódios mantidos na minissérie, a conformação da obra literária aos moldes das narrativas tradicionais de televisão estabelece-se por exclusão, omissão, junção, modificação e criação de novos episódios, que evidenciam uma generalizada simplificação, no sentido de provocar simpatia e empolgar o espectador e não fazê-lo pensar.

A simplificação das personagens, menos do que diminuir quantitativamente os temas abordados no original, restringe as possibilidades de aprofundamento das grandes questões do romance, desfigurando o universo ficcional de Raquel de Queiroz. Construindo uma nova sociedade, pautada, se não nos valores humanos mais ideais, nos possíveis dentro daquele universo que se institui, o romance de Rachel de Queiroz representa com pungência o desvalimento das populações nordestinas entregues a si mesmas. A adaptação televisiva omite o dado político-social em favor da trama amorosa e de vingança familiar, transformando a insurreição de Maria Moura em mais uma legenda de mulher guerreira - competente, mas voltada para o insólito da situação e não para suas motivações.

\section{0 ÚLTIMO CAPÍTULO}

A "necessidade da arte" como elemento essencial — e não obrigatório — da vida humana, conforme aponta Lotman (1978, p.27), tem percorrido caminhos inusitados na contemporaneidade. As inúmeras possibilidades que as tecnologias cada vez mais oferecem, as novas relações culturais possíveis num mundo globalizado permitem a criação de uma infinidade de produtos culturais, cujo hibridismo pode tornar-se desconcertante. Alguns equívocos na análise de tais manifestações muitas vezes tendem a generalizações depreciativas, quando se verifica o rompimento dos limites tradicionalmente estabelecidos pelas formas de arte canônicas.

Nas sociedades em processo de desterritorialização dos tempos que

Rev.Cad.Comun. Santa Maria, v.22, n.1, art 6, p.138 de 141, jan/abr.2018 
correm, o diálogo entre a literatura e a televisão, constituído num contexto que promove a propulsão de negócios e torna a arte um bem de consumo, pode suscitar formas de expressão concebidas a partir de padrões estéticos em que a relação tecnologia e necessidades induzidas é acentuada. Entretanto, pode também ampliar, pela estética exacerbada da imagem eletrônica, produtora de virtualidades muitos convincentes, a circulação de propostas culturais divergentes, num cenário em que as diferenças se tornam compreensíveis e sedutoras, contribuindo, talvez, para uma convivência mundial menos conturbada ou, pelo menos, divulgando um Brasil diferente daquele marcado por estereótipos, que as próprias mídias eletrônicas na maioria dos casos se encarregam de fortalecer. 
CADERNOS DE COMUNICAÇÃO

UNIVERSIDADE FEDERAL DE SANTA MARIA

\section{REFERÊNCIAS}

BAUDRILLARD, Jean. À sombra das maiorias silenciosas. São Paulo: Brasiliense, 1993.

BENJAMIM, Walter. A obra de arte na época de sua reprodutibilidade técnica. In:

LIMA, Luiz Costa (Org.). Teoria da cultura de massa. São Paulo: Paz e Terra, 1990.

BHABHA, Homi K. O local da cultura. Belo Horizonte: UFMG, 1998.

BRÜNNER, José Joaquín. Globalización cultural y posmodernidad. Santiago: Fondo de Cultura Económica, 1998.

CAPARELLI, Sérgio. Televisão e capitalismo no Brasil. Porto Alegre: L\&PM, 1982.

DUARTE, Fábio. Global e local no mundo contemporâneo: integração e conflito em escala global. São Paulo: Moderna, 1998.

FEATHERSTONE, Mike. Cultura de consumo e pós-modernismo. São Paulo: Nobel, 1995.

FERNANDES, Ismael. Memória da telenovela brasileira. São Paulo: Brasiliense, 1994.

GLEIŚER, Luiz. Novas tecnologias - a TV segmentada. In: ALMEIDA, José Mendes de; ARAÚJO, Maria Elisa de (Orgs.). As perspectivas da televisão brasileira ao vivo. Rio de Janeiro: Imago, 1995.

IANNI, Octavio. A era do globalismo. Rio de Janeiro: Civilização Brasileira, 1996.

JAMESON, Frederic. O pós-modernismo e a sociedade de consumo. In: KAPLAN, E. Ann (Org.). O mal-estar no pós-modernismo: teorias e práticas. Rio de Janeiro: Zahar, 1993.

LIMA, Fernando Barbosa Lima. A televisão brasileira. In: MACEDO, Cláudia et al (Orgs.). TV ao vivo: depoimentos. São Paulo: Brasiliense, 1988.

LOTMAN, luri. A estrutura do texto literário. Lisboa: Estampa, 1978.

LYOTARD, Jean François. O pós-moderno. Rio de Janeiro: José Olympio,1993.

MARCONDES FILHO, Ciro. Televisão. São Paulo: Scipione, 1994.

Rev.Cad.Comun. Santa Maria, v.22, n.1, art 6, p.140 de 141, jan/abr.2018 
ORTIZ, Renato. Cultura brasileira e identidade nacional. São Paulo: Brasiliense, 1994.

ROBERTSON, Roland. Mapeamento da condição global: globalização como conceito global: globalização como conceito central. In: FEATHERSTONE, Mike (Org.). Cultura global: nacionalismo, globalização, modernidade. Petrópolis: Vozes, 1994.

TÁVOLA, Artur. 0 ator: televisão em leitura crítica. Rio de Janeiro: Nova Fronteira, 1984.

\section{Maria Tereza Amodeo}

Doutora em Letras pela PUCRS, com pós-doutorado pela University of Ottawa, no Canadá (2013) na Cátedra Socio-Cultural Changes in Canada, e pela Universidade Federal do Rio de Janeiro, no Programa Avançado de Cultura Contemporânea - Pós-Doutorado em Estudos Culturais (2017). Professora titular da Escola de Humanidades - Letras da PUCRS.

RECEBIDO EM: 27/09/2017

ACEITO EM: 23/11/2017 